\title{
Variability of Two Essential Oils of Kundmannia sicula (L.) DC., A Traditional Algerian Medicinal Plant
}

\author{
Lakhdar Djarri ${ }^{1}$, Kamel Medjroubi ${ }^{1}$, Salah Akkal ${ }^{1}$, Abdelhakim Elomri ${ }^{2}$, Elisabeth \\ Seguin $^{2}$, Marie-Laure Groult ${ }^{3}$ and Philippe Vérité ${ }^{4, *}$
}

${ }^{1}$ Laboratoire Phytochimie et Analyses Physico-chimiques et Biologiques, Université Mentouri Constantine, Route de Aïn El Bey, 25000 Constantine, Algeria;

E-mail: lakhdar.djarri@etu.univ-rouen.fr

2 Laboratoire de Pharmacognosie, UFR de Médecine et de Pharmacie UMR CNRS 6014, 22 Boulevard Gambetta F-76183 Rouen cedex 1, France; E-mail: Elisabeth.Seguin@univ-rouen.fr

${ }^{3}$ Laboratoire de Botanique-Mycologie, UFR de Médecine et de Pharmacie, 22 Boulevard Gambetta F-76183 Rouen cedex 1, France; E-mail: Marie-Laure.Groult@univ-rouen.fr

${ }^{4}$ Laboratoire de Chimie Analytique, UFR de Médecine et de Pharmacie ADEN 3234, 22 Boulevard Gambetta F-76183 Rouen cedex 1, France

* Author to whom correspondence should be addressed; E-mail: Philippe.Verite@univ-rouen.fr

Received: 29 January 2008; in revised form: 27 March 2008 / Accepted: 27 March 2008 / Published: 8 April 2008

\begin{abstract}
The essential oils of the aerial parts of Kundmannia sicula (L.) DC collected from two Algerian localities, El Kala (near the coast) and Béjaia (from a meadow about 10 $\mathrm{km}$ from the coast), were analysed by GC and GC-MS. Although both samples showed similar overall chemical compositions, the major components of the Béjaia sample were identified as being spathulenol (14.8\%), caryophyllene oxide (12.2\%), salvial-4(14)en-1one (10.1\%), 1,5-epoxysalvial-4(14)ene (5.2\%) and germacrene D (3.2\%), while in the El Kala sample the main compounds were found to be salvial-4(14)en-1-one (16.4\%), 1,5epoxysalvial-4(14)ene (6.5\%), chrysanthenyl acetate (5.2\%) and $\alpha$-amorphene (2.9\%).
\end{abstract}

Keywords: Apiaceae, Kundmannia sicula, essential oil, GC-MS analysis 


\section{Introduction}

Kundmannia Scop. is a genus of the Apiaceae family which consists of about 300 genera [1, 2]. Kundmannia belong to the Oenantheae tribe and are well represented in Spain, France, Italy, Turkey, Syria and North Africa where they grow on calcareous or siliceous soils. The genus Kundmannia consists of five species: K. anatolica, endemic of Turkey [3-4], K. syriaca, endemic of Syria [5], K. insulana (Europe) [6], K. pastinacifolia [Italy (Sicily)] [7] and K. sicula (Mediterranean basin) [8-9].

In Algeria K. sicula is commonly known as "Ziyata" which means "the plant that gives a lot of oil”. This species presents leaves which are not plump, and seeds joined with the pericarp. It is a herbaceous and perennial plant presenting robust and ramified stems of 40-120 cm. Inferior leaves are glabrous and gleaming. They are disposed in rosettes applied on the ground [10]. Umbels present ten radii of 8-15 cm length. Flowers are yellow [11]. Fruits are cylindrical, glabrous and 7-10 mm in length. In traditional medicine, the roots and rhizomes are used as infusions or plasters in the treatment of inflammatory pathologies [12]. To the best of our knowledge, there are no references about the oil content and chemical composition of any Kundmannia species, therefore, in continuation of our systematic phytochemical studies of the Algerian Apiaceae [13-14], we report here the first study on two essential oils of Kundmannia sicula DC., collected at Béjaia (K.s.B) and El Kala (K.s.K).

\section{Results and Discussion}

The oil was obtained by hydrodistillation of $200 \mathrm{~g}$ of coarsely powdered dried plant material, according to the procedure described in the European Pharmacopoeia V edition [15]. The oil obtained was stored at $-4^{\circ} \mathrm{C}$ in a sealed vial until chemical analyses. Each distillation led us to obtain $0.7 \mathrm{~mL}$ of each essential oil that corresponds to yields of $0.4 \% \mathrm{v} / \mathrm{w}$.

The composition and percentages of the components are summarized in Table 1. Compounds are listed by their order of retention indice calculated on an apolar stationary phase. GC of the distilled oils revealed the presence of 27 (K.s.B) and 24 (K.s.K) components, of which 25 and 22 were identified, respectively, corresponding to $88.5 \%$ and $82.7 \%$ of the total oil compositions in each case.

The major components identified in the K.s.B essential oil were spathulenol (14.8\%), caryophyllene oxide (12.2\%), salvial-4(14)en-1-one (10.1\%), 1,5-epoxysalvial-4(14)ene (5.2\%) and germacrene D (3.9\%). The main compounds in K.s.K, were salvial-4(14)en-1-one (16.4\%), 1,5epoxysalvial-4(14)ene (6.5\%), chrysanthenyl acetate (5.2\%) and $\alpha$-amorphene (2.9\%). Monoterpene hydrocarbons $(0.2 \%)$ were only present in the K.s.B oil and oxygenated monoterpenes (5.2\%) only appeared in the K.s.K oil. Levels of oxygenated hydrocarbons in K.s.B oil were twice as high (5.2\%) as in K.s.K oil (2.3\%).

The composition of the two oil samples was dominated by sesquiterpenes: $83.2 \%$ for K.s.B and 75.1\% for K.s.K. Among these sesquiterpenes, the oxygenated ones represented $69.9 \%$ for K.s.B and $56.3 \%$ for K.s.K. These major compounds among them were identified as spathulenol (14.8\% and 2.8\%), caryophyllene oxide (12.2\% and $0 \%$ ), and salvial-4(14)en-1-one (10.1\% and 16.4\%), for K.s.B and K.s.K, respectively. 
Table 1. Percentage composition of the essential oil of the aerial parts of Kundmannia sicula DC.

\begin{tabular}{|c|c|c|c|c|c|}
\hline Peak no. & Chemical Component & MW & RI & $\begin{array}{c}\text { K.s.B } \\
(\%) F I D\end{array}$ & $\begin{array}{c}\text { K.s.K } \\
(\%) \text { FID }\end{array}$ \\
\hline 1 & $\beta$-Pinene & 136 & 976 & 0.2 & - \\
\hline 2 & Octanal & 128 & 1008 & 2.6 & 2.3 \\
\hline 3 & trans-2-Decenal & 154 & 1263 & 2.6 & - \\
\hline 4 & Chrysanthenyl acetate & 194 & 1264 & - & 5.2 \\
\hline 5 & $\alpha$-Cubebene & 204 & 1353 & 0.2 & 0.3 \\
\hline 6 & $\alpha$-Ylangene & 204 & 1377 & 0.1 & 0.2 \\
\hline 7 & $\alpha$-Copaene & 204 & 1381 & 1.1 & 1.3 \\
\hline 8 & $\beta$-Bourbonene & 204 & 1392 & 0.5 & 0.2 \\
\hline 9 & $\beta$-Elemene & 204 & 1396 & 0.7 & - \\
\hline 10 & trans-Caryophyllene & 204 & 1427 & 1.8 & 1.4 \\
\hline 11 & epi-Bicyclophellandrene & 204 & 1436 & 0.7 & 0.9 \\
\hline 12 & $\alpha$-Humulene & 204 & 1462 & 0.5 & - \\
\hline 13 & $\alpha$-Amorphene & 204 & 1482 & 1.5 & 2.9 \\
\hline 14 & Germacren D & 204 & 1489 & 3.9 & - \\
\hline 15 & $\gamma$ - Muurolene & 204 & 1500 & - & 0.7 \\
\hline 16 & $\alpha$ - Muurolene & 204 & 1505 & 0.4 & 0.7 \\
\hline 17 & $\gamma$-Cadinene & 204 & 1520 & 0.6 & 1.0 \\
\hline 18 & $\delta$-Cadinene & 204 & 1528 & 0.9 & 0.9 \\
\hline 19 & cis-Calamenene & 202 & 1530 & - & 1.8 \\
\hline 20 & $\alpha$-Calacorene & 200 & 1552 & 0.5 & 1.5 \\
\hline 21 & $\mathrm{C}_{15} \mathrm{H}_{24} \mathrm{O}$ & 220 & 1562 & 4.6 & - \\
\hline 22 & $\mathrm{C}_{15} \mathrm{H}_{26}$ & 206 & 1564 & - & 5.0 \\
\hline 23 & 1,5-Epoxysalvial-4(14)ene & 220 & 1578 & 5.2 & 6.5 \\
\hline 24 & Spathulenol & 220 & 1590 & 14.8 & 2.8 \\
\hline 25 & Caryophyllene oxide & 220 & 1596 & 12.2 & - \\
\hline 26 & Salvial-4(14)en-1-one & 220 & 1607 & 10.1 & 16.4 \\
\hline 27 & $\mathrm{C}_{15} \mathrm{H}_{24} \mathrm{O}$ & 220 & 1656 & 5.0 & 7.4 \\
\hline 28 & $\mathrm{C}_{15} \mathrm{H}_{26} \mathrm{O}$ & 222 & 1668 & - & 8.3 \\
\hline 29 & $\mathrm{C}_{15} \mathrm{H}_{24} \mathrm{O}$ & 220 & 1699 & 16.7 & 14.9 \\
\hline 30 & $\mathrm{C}_{15} \mathrm{H}_{24} \mathrm{O}$ & 220 & 1757 & 1.4 & - \\
\hline 31 & Unknown A & 236 & 1783 & 4.2 & - \\
\hline 32 & Unknown B & 234 & 1855 & 7.3 & 1.1 \\
\hline 33 & Unknown C & 238 & 1921 & - & 9.7 \\
\hline
\end{tabular}

\begin{tabular}{|l|c|c|}
\hline Monoterpene hydrocarbons & 0.2 & - \\
Oxygenated monoterpenes & - & 5.2 \\
Sesquiterpene hydrocarbons & 13.2 & 18.8 \\
Oxygenated sesquiterpenes & 67.0 & 56.3 \\
Oxygenated hydrocarbons & 5.2 & 2.3 \\
\hline
\end{tabular}

MW: molecular weight

RI: retention indice

K.s.B: Kundmannia sicula Béjaia

K.s.K: Kundmannia sicula El Kala 
These compounds were frequently observed in the essential oils of other Apiaceae species growing in countries of the Mediterranean basin, for example Eryngium maritimum grown in Turkey [16]. The percentage of sesquiterpene hydrocarbons was less abundant in K.s.B oil (13.2\% or five times less than the oxygenated sesquiterpenes in the same sample) than in K.s.K oil (18.8\% or three times less than the oxygenated sesquiterpenes in the sample). For the compounds listed in Table 1 as 21, 27, 28, 29, 30, whose mass spectral data are given in Table 2, the molecular weights and the retention indices led us to also identify them as oxygenated sesquiterpenoids.

Table 2. Mass spectral data (m/z (relative intensity)) of known molecular formula components.

\begin{tabular}{|c|c|c|c|}
\hline Peak no & RI & MW & $\mathbf{m} / \mathbf{z}(\%)$ \\
\hline 21 & 1562 & 220 & {$\left[\mathrm{M}^{+}\right]$(12), 159 (36), 146 (37), 131 (66), 123 (100), 109 (55), 91 (60), 79 (40), 67 (22) } \\
\hline 22 & 1564 & 206 & {$\left[\mathrm{M}^{+}\right]$(44), 163 (63), 145 (27), 135 (28), 123 (100), 107 (40), 93 (69), 79 (76), 67 (25) } \\
\hline 27 & 1656 & 220 & $\begin{array}{l}{\left[\mathrm{M}^{+}\right] \text {(16), } 205 \text { (22), } 177 \text { (66), } 133 \text { (31), } 123 \text { (100), } 107 \text { (38), } 91 \text { (45), } 82 \text { (68), } 77 \text { (29), }} \\
67 \text { (45) }\end{array}$ \\
\hline 28 & 1668 & 222 & $\begin{array}{l}{\left[\mathrm{M}^{+}\right] \text {(23), } 194(7), 179(7), 165 \text { (25), } 151 \text { (100), } 133 \text { (46), } 111 \text { (41), } 95 \text { (70), } 81 \text { (73), }} \\
67(28)\end{array}$ \\
\hline 29 & 1699 & 220 & {$\left[\mathrm{M}^{+}\right]$(60), 177 (25), 159 (100), 131 (28), 118 (30), 105 (41), 91 (47), 79 (30), 67 (25) } \\
\hline 30 & 1757 & 220 & {$\left[\mathrm{M}^{+}\right]$(18), 177 (26),159 (20), 150 (100), 135 (25), 107 (32), 91 (28), 81 (32), 67 (17) } \\
\hline
\end{tabular}

For compound 28 ( $\mathrm{RI}=1668)$, the molecular formula $\left(\mathrm{C}_{15} \mathrm{H}_{26} \mathrm{O}\right)$ and the retention index were in agreement with the literature data for a sesquiterpene containing a tertiary alcohol [17]. This is confirmed by characteristic peaks at $m / z$ 194, 179, 165, 151 (base peak at [M-71] ), 95 and 81 [18]. Compound 29 (RI=1699), an unidentified oxygenated sesquiterpene, was one of the main components in both essential oil samples. Three compounds: 31 (RI=1783), 32 (RI=1855) and 33 (RI=1921), all of which eluted in the final part of the chromatograms and amounted to $11.5 \%$ and $10.8 \%$ of the total oil for K.s.B and for K.s.K, respectively, could not be identified.

\section{Conclusions}

Our GC-MS and GC-FID studies of the essential oil from $K$. sicula from two different localities of Northeast of Algeria led us to identify 27 and 24 compounds, respectively. The major components were oxygenated sesquiterpenes, among which salvial-4(14)en-1-one, spathulenol, and caryophyllene oxide were the main ones. We note that the qualitative and the quantitative composition of the two studied essential oils are close, which seems to indicate that the two specimens present a similar chemotype. The variations in the chemical composition of essential oils can be explained by the difference in the geographic origins. The origin of changes should be sought mainly in the differences in the nature of soil on the one hand and solar radiation on the other. Both factors involve the activation or inactivation of certain enzymatic groups, leading to the predominance of a particular biosynthetic pathway [19]. 


\section{Experimental}

\section{Plant Material}

Aerial parts of Kundmannia sicula (L.) DC were collected in two different regions: El Kala (Wilaya El Taref) near the coast and in a meadow in Béjaia, about $10 \mathrm{kms}$ from the coast. These two localities are situated in the eastern part of Algeria and about $400 \mathrm{kms}$ from each other. The first specimen was collected in May 2002 and identified by Dr G. de Belair (Badji Moktar University Annaba); the second was collected in June 2003 and identified by H. Laouer (Ferhat Abbas University - Setif). All samples were collected at full flowering stage and the plant material was left to dry in the shade at ambient temperature $\left(25^{\circ} \mathrm{C}\right)$. Voucher specimen was deposited in the Herbarium of National Museum of Natural History Paris with the acquisition reference P00383263.

\section{Gas chromatography}

GC-FID analysis were performed with a Varian Star 3400 CX gas chromatograph equipped with an apolar Macherey Nagel Permabond SE 52 (50 m x 0.25 mm ID x $0.25 \mu \mathrm{m}$ ) capillary column. The carrier gas was nitrogen. Chromatographic conditions were similar to those described below. Injector and FID were maintained at a temperature of $280^{\circ} \mathrm{C}$.

\section{GC-MS analysis}

GC-MS analyses were realized with an Agilent gas chromatograph 6890 equipped with an apolar Macherey Nagel Permabond SE 52 (50 m x 0.25 mm ID x $0.25 \mu \mathrm{m}$ ) capillary column. The carrier gas was helium. The oven was heated from $60^{\circ} \mathrm{C}$ to $280^{\circ} \mathrm{C}$ at a rate of $3^{\circ} \mathrm{C} / \mathrm{min}$, the final temperature was then maintained during $20 \mathrm{~min}$. The injector was maintained at a temperature of $280^{\circ} \mathrm{C}$. The GC apparatus was directly interfaced with a Hewlett Packard mass spectrometer 5973 operating either in EI, or in $\mathrm{IC}^{-\mathrm{CH}_{4}}$ mode. The transfer line was maintained at a temperature of $280^{\circ} \mathrm{C}$.

\section{Identification of components}

Compounds were identified by comparison of mass spectral data described in two libraries [NIST and Wiley 275 (1995)]. Identification was confirmed by calculating the retention indexes, determined by interpolation with retention indexes of a series of $n$-alkanes analysed with the same chromatographic conditions and compared with those described in the ADAMS library [17]. The modified Van den Dool and Kratz formula was used for the determination of retention indexes [20].

\section{Acknowledgements}

The authors are grateful to Dr. Gerard de Belair from Annaba University and Dr Hocine Laouer from Setif University for identifying the plants, to CMEP (Franco-Algerian cooperative program) and FNR (National Research Fund) for financial support. 


\section{References}

1. Scopoli, J.A. Introd. Hist. Nat. 1777; p. 116.

2. System Simulation Ltd. Index Kewensis. Index + for Windows version $1.8 \mathrm{~K}$; Oxford University Press: Oxford, UK, 1994-97.

3. Huber-Morath, A. Novitae Florae Anatolicae, Bauhinia. Zeit. Bas. Bot. Gesel. 1983, 7, 269-271.

4. Pimenov, M.G.; Leonov, M.V. The Asian Umbelliferae Biodiversity Database (ASIUM) with particular Reference to South-West Asian Taxa. Turk. J. Bot. 2004, 28, 139-145.

5. Boissier, P.E. Diagn. Pl. Orient. Ser. 1849, 1, 31.

6. Gandoger, M. Notes sur la flore espagnole. Bull. Soc. Bot. France. 1900, 47, 122-124.

7. Sweet, R. Hortus Britannicus, $2^{\text {nd }}$ Ed.; J. Ridgway: London, 1830; p. 247.

8. De Candolle, A.P. Prodromus Systematis Naturalis Regni Vegetabilis; Treuttel et Würtz: Paris, 1830; vol. 4, p. 143.

9. Fournier, P. Les quatre Flores de France Corse comprise; Editions Lechevalier: Paris, 1990; p. 683.

10. Quezel, P.; Santa, S. Nouvelle flore de l’Algérie et des régions désertiques méridionales; Editions du Centre National de la Recherche Scientifique: Paris, 1963; p. 676.

11. Battandier, J.A.; Trabut, L. Flore de l’Algérie; A. Jourdan Ed: Algiers, 1888; p. 363.

12. Rimbau, V.; Cerdan, C.; Vila, R.I. Antiinflammatory activity of some extracts from plants used in the traditional medicine of North-African countries (II). J. Phytother. Res. 1999, 13, 128-132.

13. Djarri, L.; Medjroubi, K.; Akkal, S.; Elomri, A.; Seguin, E.; Vérité, P. Composition of the essential oil of aerial parts of an endemic species of the Apiaceae of Algeria, Daucus reboudii Coss. Flavour Fragr. J. 2006, 21, 647-649.

14. Bousetla, A.; Akkal, S.; Medjroubi, K.; Louaar, S.; Azouzi, S.; Djarri, L.; Zaabat, N.; Laouer, H.; Chosson, E.; Seguin, E. Flavonoid glycosides from Ammoides pusilla (Apiaceae). Chem. Nat. Compd. 2005, 41, 95-96.

15. European Pharmacopoeia. 5th ed. Council of Europe: Strasbourg, 2005; Vol. 2, pp. 2667-2668.

16. Aslan, S.; Kartal, M. GC-MS Analysis of Eryngium maritimum L. Volatile Oil. Planta Med. 2006, 72, 340-341.

17. Adams, R.P. Identification of essential oil components by gas chromatography/mass spectrometry, $2^{\text {nd }}$ edition; Allured Publishing Corporation, Carol Stream: Illinois, 2001.

18. Waller, J.R.; Dermer, O.C. Biochemical Applications of Mass Spectrometry; John Wiley \& Sons Inc: New York, 1995; pp. 311-406.

19. Belaiche, P. Traité de Phytothérapie et d'Aromathérapie. Tome-1: l'Aromatogramme; Maloine: Paris, 1979.

20. Tranchant, J. Manuel pratique de chromatographie en phase gazeuse; Masson: Paris, 1995.

Sample availability: Contact the authors.

(C) 2008 by MDPI (http://www.mdpi.org). Reproduction is permitted for non commercial purposes. 